\author{
Asian Journal of \\ Medical and Biological Research \\ ISSN 2411-4472 (Print) 2412-5571 (Online) \\ www.ebupress.com/journal/ajmbr
}

\title{
Article \\ Incidence of clinical diseases and disorders in goats at Bangladesh Livestock Research Institute
}

Md. Nuruzzaman Munsi ${ }^{1}$, Md. Ershaduzzaman ${ }^{2}$, Sonia Akther ${ }^{1 *}$, Md. Mamunur Rahman ${ }^{3}$, Md. Habibur Rahman $^{1}$ and Mohammad Mojibur Rahman ${ }^{4}$

${ }^{1}$ Goat and Sheep Production Research Division, Bangladesh Livestock Research Institute (BLRI), Savar, Dhaka1341, Bangladesh

${ }^{2}$ System Research Division, Bangladesh Livestock Research Institute (BLRI), Savar, Dhaka-1341, Bangladesh

${ }^{3}$ Conservation and improvement of native sheep through community and commercial farming project, Bangladesh Livestock Research Institute (BLRI), Savar, Dhaka-1341, Bangladesh

${ }^{4}$ Upazila Livestock Officer (leave/deputation/training reserve post) and PhD fellow, Department of Livestock Services (DLS), Bangladesh

${ }^{*}$ Corresponding author: Sonia Akther, Goat and Sheep Production Research Division, Bangladesh Livestock Research Institute, Savar, Dhaka 1341, Bangladesh. Phone: +8801717871911; E-mail: soniahossain77@gmail.com

Received: 19 November 2018/Accepted: 13 December 2018/ Published: 30 December 2018

\begin{abstract}
The current study was performed to determine the incidence and trends of clinical diseases and disorders in Black Bengal and Jamnapari goats in order to design a set of strategies to be applied for the prevention and control of these problems in this farm. A total of 739 Black Bengal and 285 Jamnapari goats at BLRI goat research farm, Savar, Dhaka, Bangladesh were included under this study. The study was performed out during the period from January 2012 to December 2014. Diagnoses and records of clinical diseases and disorders were based on pertinent clinical history, clinical findings and laboratory tests. The major clinical diseases and disorders were determined pneumonia (37.44\%), diarrhoea (21.22\%), lameness (3.01\%), mange (2.99\%), malnutrition (2.82\%), contagious ecthyma (1.93\%) and fever (1.85\%). In case of seasons, the highest incidence was found during rainy season $(2.26 \%)$ followed by winter $(5.85 \%)$ and summer $(4.25 \%)$; whereas in respect of age groups, the highest incidence was found in growing goat $(26.14 \%)$ followed by adults $(12.15 \%)$ and kids (10.93\%). So, we may conclude that although some diseases and disorders occurred in the BLRI sheep research farm, the incidence were not high. In addition, on the basis of these findings measures should be taken for further prevention of such diseases and manifestations.
\end{abstract}

Keywords: incidence; clinical diseases and disorders; goats; breed; age

\section{Introduction}

Livestock is an important component of the mixed farming system practiced in Bangladesh for centuries. Ruminants, like goats constitute one portion of the livestock in Bangladesh and a very popular source of income for smallholder farmers. In Uganda goats are an important source of meat, milk, skins, cash, manure, savings and sociocultural values (Magona and Musisi, 1999). Small ruminants form an integral and important component of the pattern of animal production in Asia (Devendra, 1986). Most of these animals are reared under smallholder traditional management system in rural areas. The management practices of animals and geoclimatic condition of Bangladesh are favorable for the occurrence of various diseases. Goats are reared under semi-intensive system of management in Goat Research Farm in Bangladesh Livestock Research Institute (BLRI), Savar, Dhaka. Analysis of the case record gives a comprehensive idea about the disease problems at Goat Research Farm of BLRI. Although some reports on clinical case records from Ulipur Upazila Veterinary 
Hospital, Kurigram (Kabir et al., 2010), Chandanaish Upazila of Chittagong district, Bangladesh (Pallab et al., 2012) and Patuakhali Science and Technology University Veterinary Clinic (Rahman et al., 2012) are available but similar report on goats are very limited in Goat Research Farm, BLRI. Small ruminants especially goats are among the livestock species that are densely populated in Ethiopia and mostly their productivity is hampered by prevalence of different diseases (Dereje et al., 2013). In Ethiopia, 5-7 million sheep and goats die each year due to disease and the overall economic loss from meat industry due to parasitic diseases is estimated at 400 million annually.8.This study may give a comprehensive idea about the disease of goat in BLRI.

\section{Materials and Methods}

\subsection{Study area, animals and period}

The study was carried out on 1024 goats at BLRI goat research farm, Savar, Dhaka, Bangladesh. The study work was conducted during the period from January 2012 to December 2014. The study period was divided into three seasons viz. summer (March to June), rainy season (July to October) and winter (November to February) on the basis of local climatic conditions.

\subsection{Deworming, dipping and vaccination of the animals}

The goat of this farm were regularly dewormed (Endex, A-mectin plus) at three months interval, whereas dipping $(0.05 \%$ malathion) was implemented once in every month. The vaccination against PPR and tetanus was performed once in a year on regular basis in this farm.

\subsection{Diseases/disorders diagnosis and data recording}

The clinical history, clinical findings and relevant laboratory tests (Mc master, ELISA, Gram's staining, direct smear method) were considered for the diagnoses of diseases and disorders. The data were recorded properly in a particular register.

\subsection{Data analysis}

The data were analysed by using SPSS software version 12 (SPSS, Inc., Chicago, IL, USA) to determine the incidence of clinical diseases/disorders.

\section{Results and Discussion}

During the study period (2012-2014) the following diseases and disorders were recorded and their incidence were determined accordingly.

\section{Diarrhoea}

The average incidence of diarrhoea of goat in this farm irrespective of age, breed and season was $21.22 \%$ although the highest incidence (33.23\%) was seen in the year of 2014 (Table 1 and Figure 1). According to breed, the highest incidence was found in Jamunapari goats (37.19\%) followed by Black Bengal goats (15.15\%) (Table 2 and Figure 2). But Nath et al. (2014) found 6.93\% and 4.95\% prevalence of diarrhoea in Black Bengal and Jamunapari goats, respectively which were different from our present findings .Considering the seasons, rainy season have highest $6.90 \%$ incidence; summer season have $4.60 \%$ and winter season have $3.65 \%$ incidence in this farm (Table 3 and Figure 3) and the highest incidence of Jamunapari goats was found in rainy season $(17.19 \%)$ followed by winter season (10.8\%) and summer season $(9.1 \%)$ (Table 4 and Figure 4). Regarding the age, in case of Black Bengal goats the highest incidence $(15.17 \%)$ was determined in kids followed by growing (11.35\%) and adults $(3.85 \%)$ (Table 5 and Figure 5). In case of Jamunapari goats the highest incidence $(65.13 \%)$ was determined in kids followed by growing (13.37\%) and adults (6.14\%) (Table 6 and Figure 6).

\section{Dysentery}

Among three years study period dysentery occurs about $0.87 \%\left(n_{1}-344\right), 0.29 \%\left(n_{2}-334\right), 1.44 \%\left(n_{3}-346\right)$ in 2012, 2013, 2014 with the average of 0.86\% (Table 1) whereas in case of Black Bengal and Jamunapari goats, it was $0.94 \%$ and $0.70 \%$ (Table 2) in this farm. Season wise incidence which contains summer, rainy and winter season were $0.27 \%, 0.54 \%, 0.13 \%$ (Table 3 ) and $0.35 \%, 0.0 \%, 0.35 \%$ (Table 4 ) in case of Black Bengal and Jamunapari goats respectively. Kid, growing and adult goats of Black Bengal and Jamunapari breed were prevalent with $0.59 \%, 0.96 \%, 0.27 \%$ (Table 5) and $0.91 \%, 0.63 \%$ and $0.0 \%$ (Table 6) dysentery in the Goat Research Farm. 


\section{Pneumonia}

The average incidence of pneumonia in goats was 37.44\% although the incidence was higher in $2014(67.63 \%)$ than those in $2012(36.62 \%)$ and $2013(0.08 \%)$ (Table 1 and Figure 1). According to breed, the highest incidence was found in Black Bengal goats (49.66\%) followed by Jamunapari goats $(7.01 \%)$ (Table 2 and Figure 2). But Nath et al. (2014) reported $5.11 \%$ and $5.41 \%$ prevalence of pneumonia in Black Bengal and Jamunapari goats, respectively which were less than our present findings. Seasonsal incidence among Black Bengal goats was $22.86 \%, 14.61 \%$ and $12.17 \%$ in summer, rainy and winter season (Table 3 and Figure 3 ) and in Jamunapari goats highest incidence was $4.2 \%$ in summer season and $2.80 \%$ in winter season and no incidence occurred in rainy season (Table 4 and Figure 4). Amin (2015) showed that in summer season pneumonia was $6.72 \%$, in rainy season $7.61 \%$ and in winter $12.56 \%$ respectively. Regarding the age, in case of Black Bengal goats the highest incidence $(58.03 \%)$ was determined in kids followed by growing $(30.19 \%)$ and adults $(12.94 \%)$ (Table 5 and Figure 5). In case of Jamunapari goats the highest incidence (14.67\%) was determined in kids followed by growing (4.45\%) and adults (0.87\%) (Table 6 and Figure 6).

\section{Mastitis \\ In goat research farm among three years study period mastitis occurs about $0.87 \%\left(\mathrm{n}_{1}-344\right), 0.59 \%\left(\mathrm{n}_{2}-334\right)$, $2.02 \%\left(\mathrm{n}_{3}-346\right)$ in $2012,2013,2014$ with the average of $1.16 \%$ (Table 1). The disease was higher in 2014 whereas in case of Black Bengal and Jamunapari goats, it was $0.94 \%$ and $1.75 \%$ (Table 2). Seasonwise incidence which contains summer, rainy and winter season were $0.27 \%, 0.40 \%, 0.27 \%$ (Table 3) and $0.70 \%$, $0.35 \%, 0.70 \%$ (Table 4) in case of Black Bangal and Jamunapari goats respectively. Adult goats of Black Bengal and Jamunapari breed were prevalent with 1.92\% (Table 5) and 2.19\% (Table 6) mastitis in the Goat Research Farm. No incidence occurs in kids and growing.}

\section{Fever}

Goats of different ages were susceptible with fever that occurs about $2.03 \%\left(\mathrm{n}_{1}-344\right), 1.79 \%\left(\mathrm{n}_{2}-334\right), 1.73 \%$ $\left(\mathrm{n}_{3}-346\right)$ in 2012, 2013, 2014 with the average of $1.85 \%$ (Table 1) whereas in case of Black Bengal and Jamunapari goats, it was $0.94 \%$ and $0.70 \%$ (Table 2). Season wise incidence which contains summer, rainy and winter season were $0.27 \%, 0.54 \%, 0.13 \%$ (Table 3) and $0.35 \%, 0.0 \%, 0.35 \%$ (Table 4) in case of Black Bangal and Jamunapari goats respectively. Kid, growing and adult goats of Black Bengal and Jamunapari breed were prevalent with $0.59 \%, 0.96 \%, 0.27 \%$ (Table 5) and $0.91 \%, 0.63 \%$ and $0.0 \%$ (Table 6) fever in the Goat Research Farm.

\section{Enterotoxaemia}

The overall incidence of enterotoxaemia on an average in goat of this farm was $0.38 \%$, whereas the year wise incidence were $0.58 \%, 0.29 \%$ and $0.28 \%$ in 2012, 2013 and 2014, respectively (Table 1). Regarding the breed, in case of Black Bengal the incidence was $0.54 \%$.Considering the seasons, incidence of Black Bengal goats was found similar in summer and rainy season (0.27\%) (Table 3). Mohammad Rohul Amin, 2015 showed that in summer season enterotoxaemia was $1.16 \%$, in rainy season $0.68 \%$ and in winter $0.89 \%$ respectively. There were no incidence of enterotoxaemia in Jamunapari goats (Table 4).Considering the age groups, the incidence $(0.55 \%)$ was found only in adults (Table 3 ) Black Bengal goats.

\section{Actinomycosis}

Goats of different ages were susceptible with actinomycosis that occurs about $2.32 \%\left(\mathrm{n}_{1}-344\right), 0 \%\left(\mathrm{n}_{2}-334\right)$, $0.86 \%\left(\mathrm{n}_{3}-346\right)$ in $2012,2013,2014$ with the average of $1.06 \%$ (Table 1) whereas in case of Black Bengal and Jamunapari goats, it was $0.94 \%$ and $1.40 \%$ (Table 2). Season wise incidence which contains summer, rainy and winter season were $0.54 \%, 0.13 \%, 0.27 \%$ (Table 3) in case of Black Bengal and $1.40 \%$ in summer season in Jamunapari goats respectively. Kid, growing and adult goats of Black Bengal and Jamunapari breed were prevalent with $0.59 \%, 0.96 \%, 0.27 \%$ (Table 5) and $0.91 \%, 0.63 \%$ and $0.0 \%$ (Table 6) actinomycosis in the Goat Research Farm.

\section{Urolithiasis}

Urolithiasis of goat in this farm irrespective of age, breed and season was $0.57 \%$ although the highest incidence $(1.16 \%)$ was seen in the year of 2012 (Table 1) than those in $2013(0 \%)$ and $2014(0.57 \%)$. But Nath et al. (2014) found $6.93 \%$ and $4.95 \%$ prevalence of urolithiasis in Black Bengal and Jamunapari goats, respectively which were different from our present findings. Incidence of urolithiasis among Black Bengal and Jamunapari goats was $0.67 \% 0.35 \%$ (Table 2). Same incidence of urolithiasis was found in summer season and winter 
season $0.27 \%$ and in rainy season it was $0.13 \%$ (Table 4). Regarding the age, in case of Black Bengal and Jamunapari goats the highest incidence was determined in adult with the percentage of $1.10 \% 0.43 \%$ (Table 5 and 6).

\begin{abstract}
Abortion
The average incidence of abortion was $0.58 \%$ although the highest incidence $(0.89 \%)$ was seen in the year of 2013 (Table 1) than those in $2012(0.29 \%)$ and 2014 (0.57\%). But Nath et al. (2014) found 6.93\% and 4.95\% prevalence of abortion in Black Bengal and Jamunapari goats, respectively which were different from our present findings. According to breed, the highest incidence was found in Black Bengal goats $(0.81 \%)$.No abortion occur in Jamunapari goats $(0.0 \%)$ (Table 2).Considering the seasons, the highest incidence of Black Bengal goats was found in summer season $(0.40 \%)$ followed by winter season $(0.27 \%)$ and rainy season $(0.13 \%)$ (Table 3). No abortion occurs in Jamunapari goats $(0.0 \%)$. (Table 4). Regarding the age, in case of Black Bengal goats the highest incidence $(1.65 \%)$ was determined in adult whereas no incidence occure in Jamunapari goats.
\end{abstract}

\begin{abstract}
Abscess
Among three years the highest incidence of abscess of goat was found in $2014(1.44 \%)$ than $2012(0.0 \%)$ and $2013(0.89 \%)$ (Table 2). According to breed, the highest incidence was found in Jamnapari goats (1.35\%) followed by Black Bengal goats $(0.94 \%)$ (Table 2). $0.4 \%$ Abscess was found in rainy season and same incidence occur in both summer and winter season $(0.27 \%)$ in Black Bengal goats (Table 3 ) and the highest incidence of Jamnapari goats was found in rainy season (0.35\%) (Table 4). In case of Black Bangle $1.10 \%$ occur in adult, $0.48 \%$ growing and $0.29 \%$ occurs in kid (Table 5). In case of Jamunapari goats the highest incidence $(0.43 \%)$ was determined in adult jamunapari goats (Table 6).

\section{Dermatitis}

Dermatitis causes severe skin problem among all ages and breeds of goats in Goat Research Farm of BLRI. Average incidence of dermatitis was $0.28 \%$ with $0.86 \%$ incidence in 2014 and no incidence occur in 2012, 2013 (Table 1). On the other hand, Nath et al. (2014) reported $2.55 \%$ and $1.37 \%$ prevalence of dermatitis in Black Bengal and Jamnapari goats, respectively which were much higher than our present findings. In case of Black Bengal goats $0.40 \%$ dermatitis occurs throughout the year of 2012-2014 (Table 2) with $0.13 \%, 0 \%, 0.27 \%$ incidence in summer, rainy and winter season (Table 3) along with $0.24 \%$ and $0.55 \%$ in growing and adult goats (table 5). In case of Jamunapari goats no dermatitis occurs throughout the year of 2012-2014 (Table 2 and 4).
\end{abstract}

\title{
Conjunctivitis
}

Average incidence of conjunctivitis was $0.28 \%$ with $0.57 \%$ incidence in 2014 and $0 \%, 0.29 \%$ incidence occurred in 2012, 2013 (Table 1). In case of Black Bengal goats $0.40 \%$ conjunctivitis occurs throughout the year of 2012-2014 (Table 2) with $0.13 \%, 0.27 \%, 0 \%$ incidence in summer, rainy and winter season (Table 3 ) along with $0.48 \%$ and $0.27 \%$ incidence occurs in growing and adult goats (table 5). In case of Jamunapari goats no conjunctivitis occurs throughout the year of 2012-2014 (Table 2 and Table 4 and Table 6).

\section{Corneal opacity}

Average incidence of corneal opacity was $0.96 \%$ with $2.13 \%$ incidence in 2014 and $0 \%, 0.59 \%$ incidence occur in 2012, 2013 (Table 1). In case of Black Bengal goats $1.21 \%$ corneal opacity occurs throughout the year of 2012-2014 (Table 2) with $0.40 \%, 0.54 \%, 0.27 \%$ incidence in summer, rainy and winter season respectively (Table 3) along with $0.59 \%, 1.20 \%$ and $0.55 \%$ incidence occurs in kid, growing and adult goats (Table 5). In case of Jamunapari goats $0.35 \%$ corneal opacity occurs throughout the year of 2012-2014 (Table 2) with only $0.35 \%$ incidence in occurs in winter season (Table 4 ) along with $0.91 \%$ occurs in kid (Table 6 ).

\section{Contagious ecthyma}

In this farm the average incidence of contagious ecthyma of goats irrespective of age, breed and season was $1.93 \%$ although the highest incidence (3.46\%) was seen in the year of 2014 than those in $2012(1.45 \%)$ and $2013(0.89 \%)$ (Table 1 and Figure 1).Considering the breed, the highest incidence was found in Black Bengal goats $(1.21 \%)$ followed by Jamunapari goats $(0.35 \%)$ (Table 2 and Figure 2$)$. In case of seasons, the highest incidence of contagious ecthyma in Black Bengal goats was found in winter season $(1.21 \%)$ followed by summer season $(0.81 \%)$ and rainy season $(0.40 \%)$ (Table 3 and Figure 3 ) whereas the highest incidence of Jamunapari goats was found in summer season $(0.35 \%)$ followed by rainy season $(0.35 \%)$ and summer season 
(0\%) (Table 4 and Figure 4). Mohammad Rohul Amin, 2015 showed that in summer season contagious ecthyma was $1.94 \%$, in rainy season $1.22 \%$ and in winter $2.06 \%$ respectively. According to age, in case of Black Bengal goats the highest incidence was determined in growing goats $(2.17 \%)$ followed by kid $2.08 \%$ and adult $0.55 \%$ (Table 5 and Figure 5). In case of Jamunapari goats the highest incidence was determined in kid about $1.83 \%$. No incidence of contagious ecthyma occurred in growing and adult (Table 6 and Figure 6).

\title{
Mange
}

In this farm the average incidence of mange of goats irrespective of age, breed and season was $2.99 \%$ although the highest incidence (5.49\%) was seen in the year of 2014 than those in $2012(2.90 \%)$ and $2013(0.59 \%)$ (Table 1 and Figure 1).Considering the breed, the highest incidence was found in Black Bengal goats (3.92\%) followed by Jamunapari goats $(0.70 \%)$ (Table 2 and Figure 2). In case of seasons, the highest incidence of mange in Black Bengal goats was found in rainy season (1.48\%) followed by summer season $(1.35 \%)$ and winter season (1.08\%) (Table 3 and Figure 3) whereas in Jamunapari goats same incidence was found in summer season $(0.35 \%)$ and rainy season $(0.35 \%)$ than winter season $(0 \%)$ (Table 4 and Figure 4$)$. According to Rahman et al. (2014) showed that in summer season mange was found $2 \%, 1 \%$ and $2 \%$ in summer, rainy and winter season respectively. Regarding the age, in case of Black Bengal goats the highest incidence was determined in adult goats $(3.03 \%)$ followed by growing $(2.89 \%)$ and kid $(0.55 \%)$ (Table 5 and Figure 5$)$. In Jamunapari goats the highest incidence was determined in growing about $1.27 \%$. No incidence of mange occurred in kid and adult (Table 6 and Figure 6).

\section{Myiasis}

Average incidence of myiasis was $0.78 \%$ with $1.74 \%$ highest incidence in 2012 and $0.59 \%, 0.28 \%$ incidence occur in 2013, 2014 (Table 1). In case of Black Bengal goats 1.08\% myiasis occurs throughout the year of 20122014 (Table 2) with same incidence $(0.27 \%)$ and $0.54 \%$ incidence occurs in rainy season (Table 3 ) along with $0.59 \%, 0.72 \%$ and $0.82 \%$ incidence occurs in kid, growing and adult goats (Table 5). In case of Jamunapari goats $0.35 \%$ myiasis occurs throughout the year of 2012-2014 (Table 2) with $0.35 \%$ incidence occurs only in rainy season (Table 4 ) along with $0.45 \%$ in adult and no incidence occurs in kid and growing goats (Table 6 ).

\section{Malnutrition}

In this farm the average incidence of malnutrition of goats irrespective of age, breed and season was $2.82 \%$ although the highest incidence (4.62\%) was seen in the year of 2014 followed by $1.16 \%$ and $2.69 \%$ in the year 2012 and 2013 respectively (Table 1 and Figure 1). Regarding breed, the highest incidence was found in Jamunapari goats $(4.91 \%)$ followed by Black Bengal goats (2.02\%) (Table 2 and Figure 2).Considering the seasons, the highest incidence of Black Bengal goat was found in summer season (1.94\%) followed by winter season $(0.67 \%)$ and rainy season $(0.40 \%)$ (Table 3 and Figure 3 ) and the highest incidence of Jamunapari goats was found in rainy season (3.15\%) followed by winter season (1.05\%) and summer season $(0.70 \%)$ (Table 4 and Figure 4). According to age, in case of Black Bengal goatsthe highest incidence (1.48\%) was determined in kids followed by growing (1.44\%) and adults (1.10\%) (Table 5 and Figure 5). In case of Jamunapari goats the highest incidence $(5.50 \%)$ was determined in kids followed by growing $(3.18 \%)$ and adults $(1.31 \%)$ (Table 6 and Figure 6).
\end{abstract}

\section{External Wound}

According to breed, age and season incidence of external wound was $1.18 \%$ with highest $2.69 \%$ incidence occurs in 2013 and $0.29 \%, 0.57 \%$ incidence occur in 2012, 2014 (Table 1). In case of Black Bengal goats 0.13\% external wound occurs throughout the year of 2012-2014 (Table 2) with 0.13\% incidence occurs in winter season (Table 3) along with $0.29 \%$, incidence occurs only in kid without affecting growing and adult goats (Table 5). In case of Jamunapari goats 3.85\% external wound occurs throughout the year of 2012-2014 (Table 2) with $3.50 \%$ and $0.35 \%$ incidence occurs in summer and winter season (Table 4) along with $0.91 \%, 3.18 \%$ and $2.19 \%$ occurs in kid, growing and adult goats respectively (Table 6).

\section{Dystocia}

Average incidence of dystocia was $0.96 \%$ with $0.29 \%, 0.59 \%$, and $0.59 \%$ incidence occurs in 2012, 2013, 2014 respectively (Table 1). In this farm incidence of dystocia mainly occur in Black Bengal goats with the incidence of $0.40 \%$ (Table 2). In summer $0.27 \%$ and in rainy season $0.13 \%$ (Table 3 ) dystocia mainly affect adult goats with $0.82 \%$ in this farm (Table 5 ). 
Metritis

Average incidence of metritis was $0.96 \%$ with $0.29 \%, 0.59 \%$, and $0.59 \%$ incidence occurs in 2012, 2013, 2014 respectively (Table 1). In this farm incidence of metritis mainly occur in Black Bengal goats with the incidence of $0.40 \%$ (Table 2). In summer $0.27 \%$ and in rainy season $0.13 \%$ (Table 3) metritis mainly affect adult goats with $0.82 \%$ in this farm (Table 5).

\section{Pregnancy Toxaemia}

The average incidence of pregnancy toxaemia of goats regardless of age, sex and season was $0.07 \%$, whereas the yearwise incidence were $0 \%, 0 \%$ and $0.22 \%$ in 2012, 2013 and 2014, in due succession (Table 1). Considering the seasons, the incidence $(0.05 \%)$ was found only in summer $(0.05 \%)$ (Table 2$)$. For age groups, reasonably the incidence $(0.10 \%)$ was found only in adults (Table 3$)$. This is, however, an indication of very good management practices in the farm.

\section{Tympany/Bloat}

The average incidence of tympany/bloat in goat of this farm irrespective of breed, age, sex and season was $1.65 \%$ although the highest incidence was seen in the year of $2013(1.79 \%)$ (Table 1). Regarding breed, the highest incidence was found in Jamunapari goats (1.79\%) followed by Black Bengal goats (1.62\%) (Table 2).The highest incidence was found in rainy season (0.81\%) and in case of Black Bengal (1.44\%) (Table 5) and Jamunapari (1.27\%) (Table 6) highest incidence was noticed in growing goats.

\section{Hypothermia}

Average incidence of hypothermia was $0.77 \%$ with $0.58 \%, 0 \%$ and $1.73 \%$ incidence occurs in 2012, 2013, 2014 respectively (Table 1). In this farm incidence of hypothermia mainly occur in Black Bengal goats with the incidence in summer season was $0.81 \%$ (Table 3 ) and kids were $2.08 \%$ susceptible with hypothermia (Table 5). In case of Jamunapari goats no incidence of hypothermia occurs.

Table 1. Overall incidence of clinical diseases and disorders in goats at BLRI goat research farm (20122014).

\begin{tabular}{lllll}
\hline \multirow{2}{*}{ Disease/Disorder } & \multicolumn{4}{c}{ Incidence of diseases and disorders $(\%)$} \\
\cline { 2 - 5 } & $\mathbf{2 0 1 2}\left(\mathbf{n}_{\mathbf{1} \mathbf{3}} \mathbf{3 4 4}\right)$ & $\mathbf{2 0 1 3}\left(\mathbf{n}_{\mathbf{2}=\mathbf{3 3 4})}\right)$ & $\mathbf{2 0 1 4}\left(\mathbf{n}_{\mathbf{3} \mathbf{3} \mathbf{3 4 6})}\right.$ & Average \\
\hline Diarrhoea & 13.08 & 17.36 & 33.23 & 21.22 \\
Dysentery & 0.87 & 0.29 & 1.44 & 0.86 \\
Pneumonia & 36.62 & 8.08 & 67.63 & 37.44 \\
Mastitis & 0.87 & 0.59 & 2.02 & 1.16 \\
Fever & 2.03 & 1.79 & 1.73 & 1.85 \\
Teat crack & 0.29 & 1.19 & 0.28 & 0.68 \\
Enterotoxaemia & 0.58 & 0.29 & 0.28 & 0.38 \\
Actinomycosis & 2.32 & 0 & 0.86 & 1.06 \\
Urolithiasis & 1.16 & 0 & 0.57 & 0.57 \\
Abortion & 0.29 & 0.89 & 0.57 & 0.58 \\
Abscess & 0 & 0.89 & 1.44 & 0.77 \\
Dermatitis & 0 & 0 & 0.86 & 0.28 \\
Conjunctivitis & 0 & 0.29 & 0.57 & 0.28 \\
Corneal opacity & 0 & 0.59 & 2.31 & 0.96 \\
Contagious Ecthyma & 1.45 & 0.89 & 3.46 & 1.93 \\
Mange & 2.90 & 0.59 & 5.49 & 0.99 \\
Myiasis & 1.74 & 0.59 & 0.28 & 2.82 \\
Malnutrition & 1.16 & 2.69 & 4.62 & 1.18 \\
External wound & 0.29 & 2.69 & 0.57 & 0.29 \\
Dystocia & 0.29 & 0.59 & & 0.65 \\
Tympany/Bloat & 1.45 & 1.79 & 1.73 & 0.77 \\
Hypothermia & 0.58 & 0 & 1.73 & 3.01 \\
Lameness & 0.58 & 2.39 & 6.06 & 0.49 \\
Fox bite & 0.58 & 0.89 & 0 & \\
\hline
\end{tabular}


Table 2. Breedwise overall incidence of clinical diseases and disorders in goats at BLRI goat research farm (2012-2014).

\begin{tabular}{lll}
\hline Disease/Disorder & Incidence (\%) in Black Bengal goats $\left(\mathbf{N}_{\mathbf{1}}=\mathbf{7 3 9}\right)$ & Incidence $\mathbf{( \% )}$ in Jamnapari goats $\left.\mathbf{~}_{\mathbf{2}} \mathbf{= 2 8 5}\right)$ \\
\hline Diarrhoea & 15.15 & 37.19 \\
Dysentery & 0.94 & 0.70 \\
Pneumonia & 49.66 & 7.01 \\
Mastitis & 0.94 & 1.75 \\
Fever & 1.21 & 3.50 \\
Teat crack & 0.27 & 1.75 \\
Enterotoxaemia & 0.54 & 0 \\
Actinomycosis & 0.94 & 1.40 \\
Urolithiasis & 0.67 & 0.35 \\
Abortion & 0.81 & 0 \\
Abscess & 0.94 & 1.35 \\
Dermatitis & 0.40 & 0 \\
Conjunctivitis & 0.40 & 0 \\
Corneal opacity & 1.21 & 0.35 \\
Contagious Ecthyma & 2.43 & 0.70 \\
Mange & 3.92 & 0.70 \\
Myiasis & 1.08 & 0.35 \\
Malnutrition & 2.02 & 4.91 \\
External wound & 0.13 & 3.85 \\
Dystocia & 0.40 & 0 \\
Tympany/Bloat & 1.62 & 1.75 \\
Hypothermia & 0 & 0 \\
Lameness & 0.67 & 9.12 \\
Fox bite & 0.67 & 0 \\
\hline
\end{tabular}

Table 3. Seasonwise overall incidence of clinical diseases and disorders in Black Bengal goats at BLRI goat research farm (2012-2014).

\begin{tabular}{llll}
\hline \multirow{2}{*}{ Disease/Disorder } & \multicolumn{3}{c}{ Incidence (\%) in Black Bengal goats $\left.\mathbf{( N}_{\mathbf{1}}=\mathbf{7 3 9}\right)$} \\
\cline { 2 - 4 } & Summer Season (March-June) & $\begin{array}{l}\text { Rainy Season } \\
\text { (July -October) }\end{array}$ & $\begin{array}{l}\text { Winter Season } \\
\text { (November-February) }\end{array}$ \\
\hline Diarrhoea & 4.60 & 6.90 & 3.65 \\
Dysenery & 0.27 & 0.54 & 0.13 \\
Pneumonia & 22.86 & 14.61 & 12.17 \\
Mastitis & 0.27 & 0.40 & 0.27 \\
Fever & 0.13 & 0.54 & 0.54 \\
Teat crack & 0.13 & 0.13 & 0 \\
Enterotoxaemia & 0.27 & 0.27 & 0 \\
Actinomycosis & 0.54 & 0.13 & 0.27 \\
Urolithiasis & 0.27 & 0.13 & 0.27 \\
Abortion & 0.40 & 0.13 & 0.27 \\
Abscess & 0.27 & 0.40 & 0.27 \\
Dermatitis & 0.13 & 0 & 0.27 \\
Conjunctivitis & 0.13 & 0.27 & 0 \\
Corneal opacity & 0.40 & 0.54 & 0.27 \\
Contagious Ecthyma & 0.81 & 0.40 & 1.21 \\
Mange & 1.35 & 1.48 & 1.08 \\
Myiasis & 0.27 & 0.54 & 0.27 \\
Malnutrition & 1.94 & 0.40 & 0.67 \\
External wound & 0 & 0 & 0.13 \\
Dystocia & 0.27 & 0.13 & 0 \\
Tympany/Bloat & 0.54 & 0.81 & 0.27 \\
Hypothermia & 0.81 & 0 & 0.27 \\
Lameness & 0.27 & 0.13 & 0.27 \\
Fox bite & 0.27 & 0.27 & 0.13 \\
\hline & & & \\
\hline
\end{tabular}


Table 4. Seasonwise overall incidence of clinical diseases and disorders in Jamnaparigoats at BLRI goat research farm (2012-2014).

\begin{tabular}{llll}
\hline Disease/Disorder & \multicolumn{3}{c}{$\begin{array}{c}\text { Incidence (\%) in Jamnapari goats } \\
\text { ( } \mathbf{N}_{\mathbf{2}}=\mathbf{2 8 5} \text { ) }\end{array}$} \\
\cline { 2 - 4 } & $\begin{array}{l}\text { Summer Season (March- } \\
\text { June) }\end{array}$ & $\begin{array}{l}\text { Rainy Season } \\
\text { (July -October) }\end{array}$ & $\begin{array}{l}\text { Winter Season } \\
\text { (November-February) }\end{array}$ \\
\hline Diarrhoea & 9.1 & 17.19 & 10.8 \\
Dysenery & 0.35 & 0 & 0.35 \\
Pneumonia & 4.2 & 0 & 2.80 \\
Mastitis & 0.70 & 0.35 & 0.70 \\
Fever & 1.05 & 0.70 & 1.75 \\
Teat crack & 0 & 0.35 & 1.40 \\
Enterotoxaemia & 0 & 0 & 0 \\
Actinomycosis & 1.40 & 0 & 0 \\
Urolithiasis & 0 & 0.35 & 0 \\
Abortion & 0 & 0 & 0 \\
Abscess & 0 & 0.35 & 0 \\
Dermatitis & 0 & 0 & 0 \\
Conjunctivitis & 0 & 0 & 0 \\
Corneal opacity & 0 & 0 & 0.35 \\
Contagious Ecthyma & 0.35 & 0.35 & 0 \\
Mange & 0.35 & 0.35 & 0 \\
Myiasis & 0 & 0.35 & 0 \\
Malnutrition & 0.70 & 3.15 & 1.05 \\
External wound & 3.50 & 0 & 0.35 \\
Dystocia & 0 & 0 & 0 \\
Tympany/Bloat & 0 & 0.35 & 1.40 \\
Hypothermia & 0 & 0 & 0 \\
Lameness & 3.85 & 3.50 & 1.75 \\
Fox bite & 0 & 0 & 0 \\
\hline
\end{tabular}

Table 5. Agewise overall incidence of clinical diseases and disorders in Black Bengal goats at BLRI goat research farm (2012-2014).

\begin{tabular}{llll}
\hline \multirow{2}{*}{ Disease/Disorder } & \multicolumn{3}{c}{ Incidence (\%) at different stages of Black Bengal goats } \\
\cline { 2 - 4 } & Kid (0-3 months) $\left(\mathbf{n}_{\mathbf{B}} \mathbf{3 3 6}\right)$ & $\begin{array}{l}\text { Growing(>3-6 months) } \\
\left(\mathbf{n}_{\mathbf{n}} \mathbf{4 1 4}\right)\end{array}$ & Adult $\left(>\mathbf{6}\right.$ months) $\left(\mathbf{n}_{\mathbf{B}} \mathbf{3 6 3}\right)$ \\
\hline Diarrhoea & 15.17 & 11.35 & 3.85 \\
Dysenery & 0.59 & 0.96 & 0.27 \\
Pneumonia & 58.03 & 30.19 & 12.94 \\
Mastitis & 0 & 0 & 1.92 \\
Fever & 1.48 & 0.72 & 0.27 \\
Teat crack & 0 & 0 & 0.55 \\
Enterotoxaemia & 0 & 0.48 & 0.55 \\
Actinomycosis & 0.89 & 0.96 & 0 \\
Urolithiasis & 0 & 0.24 & 1.10 \\
Abortion & 0 & 0 & 1.65 \\
Abscess & 0.29 & 0.48 & 1.10 \\
Dermatitis & 0 & 0.24 & 0.55 \\
Conjunctivitis & 0 & 0.48 & 0.27 \\
Corneal opacity & 0.59 & 1.20 & 0.55 \\
Contagious Ecthyma & 2.08 & 2.17 & 0.55 \\
Mange & 1.78 & 2.89 & 3.03 \\
Myiasis & 0.59 & 0.72 & 0.82 \\
Malnutrition & 1.48 & 1.44 & 1.10 \\
External wound & 0.29 & 0 & 0 \\
Dystocia & 0 & 0 & 0.82 \\
Tympany/Bloat & 0.59 & 1.44 & 1.10 \\
Hypothermia & 2.08 & 0.24 & 0 \\
Lameness & 0.59 & 0.48 & 0.55 \\
Fox bite & 0.29 & 0.72 & 0.07 \\
\hline & & & \\
\hline
\end{tabular}


Table 6. Age wise overall incidence of clinical diseases and disorders in Jamnapari goats at BLRI goat research farm (2012-2014).

\begin{tabular}{llll}
\hline \multirow{2}{*}{ Disease/Disorder } & \multicolumn{3}{c}{ Incidence (\%) at different stages of Jamnapari goats } \\
\cline { 2 - 4 } & Kid (n=109) & Growing $(\mathbf{n = 1 5 7})$ & Adult $(\mathbf{n}=\mathbf{2 2 8})$ \\
\hline Diarrhoea & 65.13 & 13.37 & 6.14 \\
Dysenery & 0.91 & 0.63 & 0 \\
Pneumonia & 14.67 & 4.45 & 0.87 \\
Mastitis & 0 & 0 & 2.19 \\
Fever & 7.33 & 0 & 0.87 \\
Teat crack & 0 & 0 & 2.19 \\
Enterotoxaemia & 0 & 0 & 0 \\
Actinomycosis & 0 & 2.54 & 0 \\
Urolithiasis & 0 & 0 & 0.43 \\
Abortion & 0 & 0 & 0 \\
Abscess & 0 & 0 & 0.43 \\
Dermatitis & 0 & 0 & 0 \\
Conjunctivitis & 0 & 0 & 0 \\
Corneal opacity & 0.91 & 0 & 0 \\
Contagious Ecthyma & 1.83 & 0 & 0 \\
Mange & 0 & 1.27 & 0 \\
Myiasis & 0 & 0 & 0.45 \\
Malnutrition & 5.50 & 3.18 & 1.31 \\
External wound & 0.91 & 3.18 & 2.19 \\
Dystocia & 0 & 0 & 0 \\
Tympany/Bloat & 0.91 & 1.27 & 0.87 \\
Hypothermia & 0 & 0 & 0 \\
Lameness & 4.58 & 7.64 & 3.94 \\
Fox bite & 0 & 0 & 0 \\
\hline
\end{tabular}

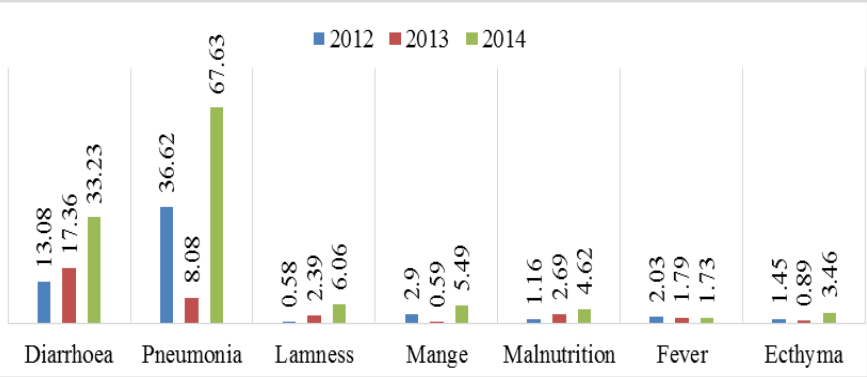

Figure 1. Year wise incidence of major clinical diseases and disorders in goats at BLRI goat research farm.

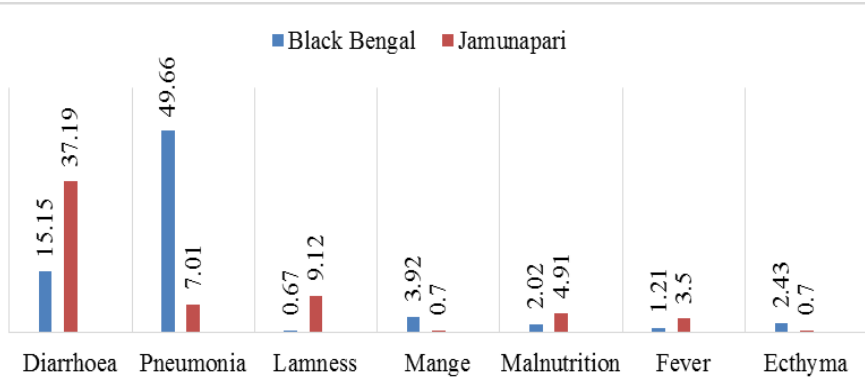

Figure 2. Breedwise incidence of major clinical diseases and disorders in goats at BLRI goat research farm. 


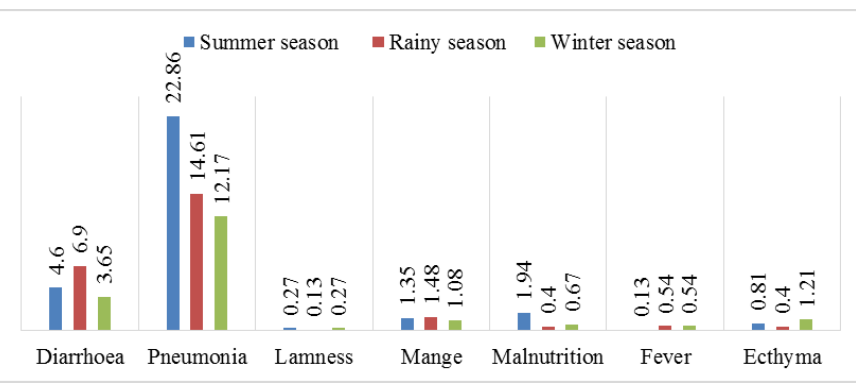

Figure 3. Season wise incidence of major clinical diseases and disorders in Black Bengal goats at BLRI goat research farm.

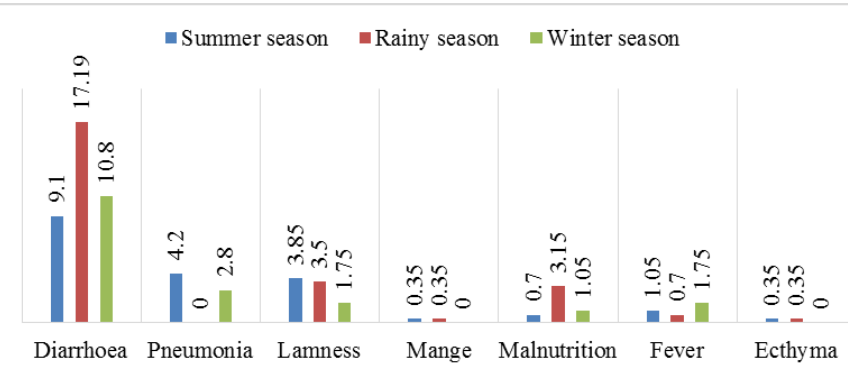

Figure 4. Seasonwise incidence of major clinical diseases and disorders in Jamnapari goats at BLRI goat research farm.

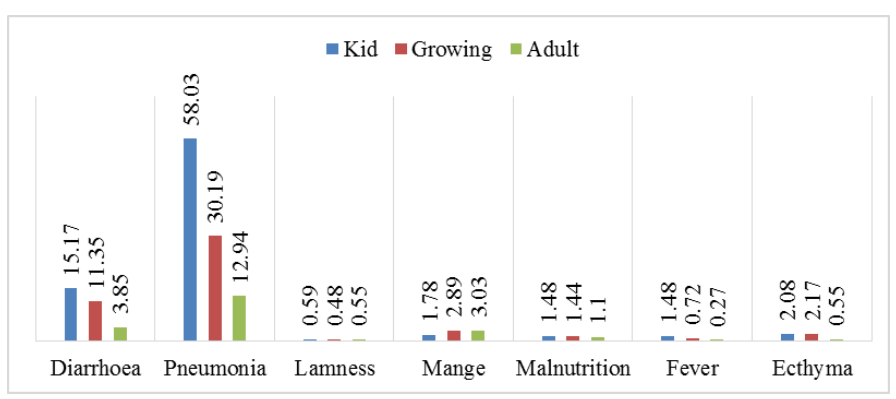

Figure 5. Age wise incidence of major clinical diseases and disorders in Black Bengal goats at BLRI goat research farm.

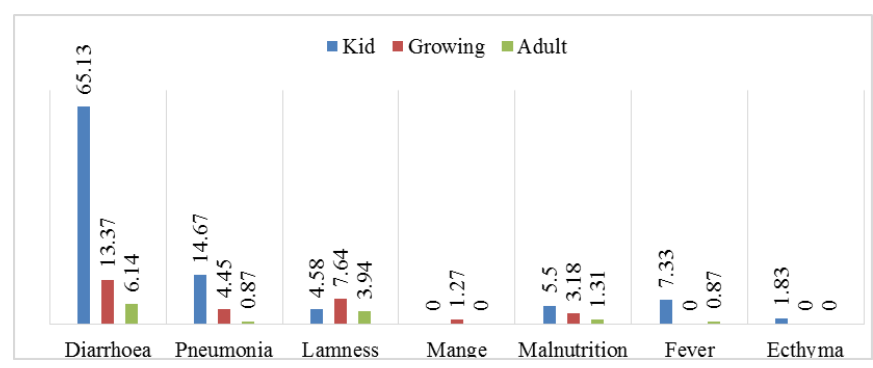

Figure 6. Agewise incidence of major clinical diseases and disorders in Jamnapari goats at BLRI goat research farm.

\section{Lameness}

Lameness was $3.01 \%$ although the highest incidence $(6.06 \%$ ) was seen in the year of 2014 followed by $0.58 \%$ and 2.39\% in the year 2012 and 2013 respectively(Table 1 and Figure 1). Regarding breed, the highest incidence was found in Jamnapari goats $(9.12 \%)$ followed by Black Bengal goats $(0.67 \%)$ (Table 2). Considering the seasons, same incidence of Black Bengal goats was found in summer season $(0.27 \%)$ and winter season $(0.27 \%)$ followed by rainy season $(0.13 \%)$ (Table 3 and Figure 3) and the highest incidence of Jamnapari goats was found in summer season (3.85\%) followed by rainy season (3.50\%) and winter season (1.75\%) (Table 4). 
According to age, in case of Black Bengal goats the highest incidence $(0.59 \%)$ was determined in kids followed by adult $(0.55 \%)$ and growing $(0.48 \%)$ (Table 5$)$. In case of Jamnapari goats the highest incidence (7.64\%) was determined in growing followed by kid (4.58\%) and adults (3.94\%) (Table 6).

\section{Fox Bite}

Average incidence of fox bite was $0.49 \%$ with $0.58 \%, 0.89 \%$ in 2012, 2013 respectively (Table 1). In this farm incidence of fox bite mainly occur in Black Bengal goats with the incidence of $0.67 \%$ (Table 2). In summer and winter same as $0.27 \%$ and in rainy season $0.13 \%$ (Table 3). Age wise incidence was $0.29 \%, 0.72 \%$ and $0.07 \%$ respectively in this farm (Table 5).

\section{Conclusions}

The overall average incidence of major clinical diseases and disorders recorded during clinical examination of sick animals (goats) at BLRI goat research farm, Savar, Dhaka Bangladesh were diarrhoea (5.18\%), malnutrition $(2.85 \%)$, lameness $(1.93 \%)$, pneumonia $(1.02 \%)$, alopecia $(0.88 \%)$, tapeworm infection $(0.81 \%)$ and fever $(0.51 \%)$. Thus, we can concluded that although some diseases and disorders took place in the BLRI goat research farm, the incidence were very low and most of the infectious diseases did not occur because of proper management of the farm particularly regular deworming, dipping and vaccination. Moreover, on the basis of these findings measures should be taken for further prevention of such diseases and disorders.

\section{Acknowledgements}

The authors express their special thanks to the Scientist of Conservation and improvement of native sheep through community and commercial farming project, Bangladesh Livestock Research Institute (BLRI), Savar, Dhaka-1341, Bangladesh for their kind co-operation.

\section{Conflict of interest}

None to declare.

\section{References}

Tsegaye D, B Belay and A Haile, 2013. Prevalence of major goat diseases and mortality of goat in Daro-Labu District of West Hararghe, Eastern Ethiopia. Int. J. Sci. Innov. Res., 2: 665-672.

Devendra C, 1986. Prospect for Developing Small Ruminant Production in Humid Tropical Africa: Small Ruminant Production in the developing Countries. Editedby TimonVM and Hanrahan. FAO Animal Production and Health Paper 58, Rome, pp.184-198.

Kabir MH, MA Reza, KMA Razi, MM Parvez, MAS Bag and SU Mahfuz, 2010. A report on clinical prevalence of diseases and disorders in cattle and goat at the Upazilla Veterinary Hospital, Ulipur, Kurigram. International Journal of Biological Research, 2: 17-23.

Rahma MA, Sharifuzzaman, JU Khokon, EH Sarker, M Shahiduzzaman, M Mostofa, 2014. Prevalence of parasitic diseases of goat at Pirganj upazilla of Bangladesh. Int. J. Nat. Soc. Sci., 1: 8-12.

Magona JW and G Musisi, 1999. Prevalence and infection levels of gastrointestinal nematodes in Ugandan goats in different agroclimatic zones. Bulletin of Animal Health and Production in Africa, 47: 49-56.

Amin MR, 2015. Prevalence of common parasitic and infectious diseases of goat at Babugonj upazilla, Barisal, Bangladesh. Asian J. Med. Biol. Res., 1: 449-456.

Munsi MN, MA Yousuf and SMJ Hossain, 2015. Dynamics of clinical disease prevalence at cattle farm in Bangladesh Livestock Research Institute, Savar, Dhaka, Bangladesh from 2011 to 2014. Asian J. Med. Biol. Res., 1: 350-358.

Nath TC, MJU Bhuiyan, MA Mamun, R Datta, SK Chowdhury, M Hossain and MS Alam 2014. Common Infectious Diseases of Goats in Chittagong District of Bangladesh. Int. J. Sci. Res. Agric. Sci., 1: 43-49.

Pallab MS, SM Ullah, MM Uddin and OF Miazi, 2012. A cross sectional study of several diseases in cattle at Chandanaish Upazilla of Chittagong district, Bangladesh. Scientific Journal of Veterinary Advances, 1: 2832.

Rahman MA, MA Islam, MA Rahman, AK Talukder, MS Parvin, and MT Islam, 2012. Clinical diseases of ruminants recorded at the Patuakhali Science and Technology University Veterinary Clinic. Bang. J. Vet. Med., 10: 63-73.

Sileshi Z and D Lidetu, 2003. Control of internal parasites in sheep and goats. In: technical bulletin no.3 Control of internal parasites in sheep and goats (Eds.) L. Dawson, R.C. www.esgpip.org/PDF/ Technical\%20bulletin\%20No .3.pdf. 